\title{
USO DE TESTES COLORIMÉTRICOS NA AVALIACCÃO DA VIABILIDADE POLÍNICA DO URUCUM (Bixa orellana L.)
}

Kátia Fabiane Medeiros Schmitt ${ }^{1}$; Rafael Pereira de Paula ${ }^{2}$; Eliane Cristina Moreno ${ }^{3}$; Auana Vicente Tiago ${ }^{4}$; Ana Aparecida Bandini Rossi ${ }^{5}$.

${ }^{1}$ Graduanda em Ciências Biológicas, Universidade do Estado de Mato Grosso UNEMAT, Campus de Alta Floresta, MT, Brasil. E-mail: kmedeirosschmitt@gmail.com.

${ }^{2}$ Graduando em Agronomia, Universidade do Estado de Mato Grosso - UNEMAT, Campus de Alta Floresta, MT, Brasil.

${ }^{3}$ Bióloga, Universidade do Estado de Mato Grosso - UNEMAT, Campus de Alta Floresta, MT, Brasil.

${ }^{4}$ Mestranda do Programa de Pós-Graduação em Biodiversidade e Agroecossistemas Amazônicos - PPGBioAgro, Universidade do Estado de Mato Grosso - UNEMAT, Campus de Alta Floresta, MT, Brasil.

${ }^{5}$ Doutora em Genética e Melhoramento. Professora da Faculdade de Ciências Biológicas e Agrárias, Universidade do Estado de Mato Grosso - UNEMAT, Campus de Alta Floresta, MT, Brasil.

Recebido em: 08/09/2015 - Aprovado em: 14/11/2015 - Publicado em: 01/12/2015 DOI: http://dx.doi.org/10.18677/Enciclopedia_Biosfera_2015_243

Objetivou-se neste estudo avaliar a viabilidade polínica de botões florais em préantese de Bixa orellana utilizando testes colorimétricos, visando auxiliar em futuros estudos de manejo e melhoramento vegetal. Foram coletados botões florais de cinco genótipos (indivíduos) de $B$. orellana em três populações, sendo estas nos municípios de Nova Canaã do Norte (NC), Alta Floresta (AF) e Nova Bandeirantes (NB) no norte do estado de Mato Grosso. Em cada genótipo foram coletados cinco botões florais em pré-antese no período da manhã. O material coletado foi fixado em solução etanol - ácido acético glacial na proporção 3:1 e deixado em temperatura ambiente por 24 horas, em seguida transferido para a álcool 70\% e armazenado em geladeira para posteriores análises. Para estimar a viabilidade polínica foram utilizados os corantes: Carmim acético $2 \%$, Lugol e Reativo de Alexander. Os dados foram submetidos à análise de variância e as médias comparadas pelo teste de Tukey $(p \leq 0.05)$ com o auxilio do programa estatístico SISVAR 4.6. Os três corantes utilizados foram capazes de distinguir os polens viáveis dos inviáveis. Não houve diferença estatística entre os corantes analisados. Já na comparação entre as populações independente do corante, observa-se que a população de Nova Bandeirantes obteve média de $87,72 \%$ diferindo-se estatisticamente das demais populações que mantiveram médias $>90 \%$. A espécie $B$. orellana apresentou alta viabilidade polínica.

PALAVRAS-CHAVE: Bixaceae; Fertilidade masculina; Pólen. 


\title{
USE COLORIMETRIC TEST ON POLLEN VIABILITY OF URUCUM (Bixa orellana
}

\author{
L.)
}

\begin{abstract}
The aim of this study was to evaluate the pollen viability of flower buds in pre anthesis Bixa orellana using colorimetric tests, aiming to help in future studies of management and plant breeding. Flower buds were collected from five genotypes (individuals) of $\mathrm{B}$. orellana in three populations, which are in the cities of Nova Canaã do Norte (NC), Alta Floresta (AF) and Nova Bandeirantes (NB), in the north of Mato Grosso. In each genotype were collected five flower buds in pre anthesis in the morning. The collected material was fixed in ethanol solution - glacial acetic acid in 3: 1 ratio and leaving at room temperature for 24 hours, then transferred to $70 \%$ ethanol and stored in a refrigerator for further analysis. To estimate pollen viability dyes were used: acetic Carmine 2\% Lugol and Reactive Alexander. Data were subjected to analysis of variance and means compared by Tukey test $(p \leq 0.05)$ with the help of statistical program SISVAR 4.6. The three dyes used were able to distinguish viable from non-viable pollen. There was no statistical difference between the analyzed dyes. In the comparison between independent populations of the dye, it is observed that the population of Nova Bandeirantes had an average of $87.72 \%$ differing statistically from the other populations that have maintained average $>90 \%$. Dyes were efficient in the distinction of viable pollen grains of unviable, and the average viability ranged from $87.64 \%$ to $93.92 \%$ and can be used any of the three in the analysis of pollen viability of the species.
\end{abstract}

KEYWORDS: Bixaceae; Masculine fertility; Pollen.

\section{INTRODUÇÃO}

O urucum é uma planta perene pertencente à família das Bixaceae, nativa da América tropical é a única espécie do gênero Bixa. É de suma importância para indústria alimentícia e farmacológica, principalmente como corante natural e também muito utilizado entre as populações indígenas. A espécie pode alcançar de 2 a 9 metros de altura e é conhecida popularmente no Brasil como urucu, urucum ou colorau, que é um pó de coloração vermelho alaranjado, de sabor e odor próprios, de ação conservante, utilizado como componente de diversos pratos da culinária brasileira (LIMA, 2013).

Segundo BONFIM et al., (2015), as flores do urucum são agrupadas terminalmente em uma inflorescência do tipo cacho de monocásio, são actinomorfas, cíclicas, hermafroditas, pentâmeras e possuem numerosos estames com anteras de deiscência poricida. Possuem pólen em abundância, mas não produzem néctar e começam a abrir pouco antes do amanhecer, em torno das $5 \mathrm{~h}$, demorando cerca de uma hora para abrir totalmente. O principal polinizador da espécie são as abelhas.

Os frutos são cápsulas de duas partes, que contém de 30 a 45 sementes, podendo ser ovóides, cordiformes, esféricos e achatados, sua coloração varia do verde ao vermelho intenso. A colheita dos frutos ocorre em dois períodos, à primeira de fevereiro a março e a segunda de agosto a setembro. Após colheita que na maioria das vezes é realizada manualmente, os frutos são secos e, em seguida, beneficiados. $O$ beneficiamento é realizado manualmente ou por meio de máquinas apropriadas (CARVALHO et al., 2010).

Por apresentar crescimento rápido, o urucum pode ser plantado em conciliação com outras espécies em áreas degradadas de preservação permanente destinada à 
recomposição da vegetação (LORENZI, 1998). Possui um dos poucos corantes de uso permitido pela Organização Mundial de Saúde, por não ser tóxico. Bixa orellana é uma espécie pioneira, característica da floresta amazônica, sendo as sementes condimentares e tinturiais, muito aproveitada na indústria (BARBIERI, 2011).

São poucos os estudos sobre a viabilidade dos polens de $B$. orellana, portanto segundo RIGAMOTO \& TYAGI (2002), testar a viabilidade do gametófito masculino destas flores é indispensável, pois a quantidade e a qualidade do pólen produzido por flor são componentes determinantes que têm influência direta no sucesso da fertilização.

O comportamento dos grãos de pólen em qualquer espécie vegetal é de fundamental importância para o estudo e detalhamento genético da planta (CORRÊA et al., 2005). Os métodos colorimétricos são muito utilizados para testar a viabilidade dos polens, são corantes químicos específicos que reagem com componentes celulares presentes no grão de pólen maduro. Dentre estes, destacam-se o lugol, carmim acético e a solução de Alexander (PAGLIARINI \& POZZOBON, 2004).

Portanto, objetivou-se neste estudo avaliar a viabilidade polínica de botões florais em pré-antese de Bixa orellana utilizando testes colorimétricos, visando auxiliar futuros estudos de manejo e melhoramento vegetal.

\section{MATERIAL E MÉTODOS}

O presente trabalho foi realizado no Laboratório de Genética Vegetal e Biologia Molecular da Universidade do Estado de Mato Grosso (UNEMAT), Campus Universitário de Alta Floresta, MT.

Foram coletados botões florais de cinco genótipos (indivíduos) de Bixa orellana em três populações, sendo estas nos municípios de Nova Canaã do Norte (NC), Alta Floresta (AF) e Nova Bandeirantes (NB), no norte do estado de Mato Grosso, no mês de janeiro de 2014. Em cada genótipo foram coletados cinco botões florais em pré antese no período da manhã.

O material coletado foi fixado em solução etanol - ácido acético glacial na proporção 3:1 e deixando em temperatura ambiente por 24 horas, e seguida transferindo para a álcool $70 \%$ e armazenado em geladeira para posteriores analises.

Para determinação da viabilidade polínica foram utilizados três corantes: carmim acético 2\% (KEARNS \& INOUYE, 1993), lugol (DAFNI, 1992) e reativo de Alexander (ALEXANDER, 1980). Segundo MUNHOZ et al., (2008) o carmim acético indica a integridade cromossômica, o lugol indica a presença de amido e o reativo de Alexander contém fucsina ácida e verde de malaquita que reagem, respectivamente, com o protoplasma e a celulose da parede do pólen.

Os grãos de pólen que se apresentaram corados, exina intacta, protoplasma bem corado com distribuição homogênea foram classificados como normais/viáveis, enquanto que os anormais/ inviáveis se apresentaram não corados, com tamanho visualmente anormal, coloção fraca, protoplasma reduzido e/ou ausente (GOMES et al., 2013)

Com o auxilio de um bisturi as anteras foram seccionadas transversalmente, em seguida depositadas sobre uma lâmina de vidro. Seguiu-se uma maceração com um bastão de vidro visando à liberação dos grãos de polens e foram adicionadas três gotas dos corantes supracitados, logo após o material foi coberto com uma 
lamínula. Para cada botão foram preparadas três lâminas, uma para cada corante, totalizando 15 lâminas por indivíduo e um total geral de 75 lâminas por população.

Foram contabilizados 500 grãos de pólen por lâminas pelo método de varredura, sob microscópio óptico binocular (Primo Star Zeiss) com lente objetiva de 40x. Com os dados obtidos, calculou-se a porcentagem de polens viáveis pela equação: Viabilidade do pólen $(\%)=\mathrm{N}^{\circ}$ de grãos cor ados $/ \mathrm{N}^{\circ}$ de grãos contados * 100.

Os dados foram submetidos á análise de variância e as médias comparadas pelo teste de Tukey a $5 \%$ de probabilidade. Todas as análises foram realizadas pelo programa estatístico SISVAR 4.6 (FERREIRA, 2011).

\section{RESULTADOS E DISCUSSÃO}

Os testes colorimétricos utilizando lugol, carmim acético e reativo de Alexander para a avaliação da viabilidade polínica de $B$. orellana foram capazes de distinguir os polens viáveis dos inviáveis conforme demonstrado na Figura 1.

Devido à reação com o material genético existente no citoplasma, como o DNA (PAGLIARINI \& POZZOBON, 2004), os grãos de polens viáveis corados com carmim acético $2 \%$ apresentaram coloração rosa/vermelha, enquanto que os inviáveis mostraram-se transparentes e não corados.

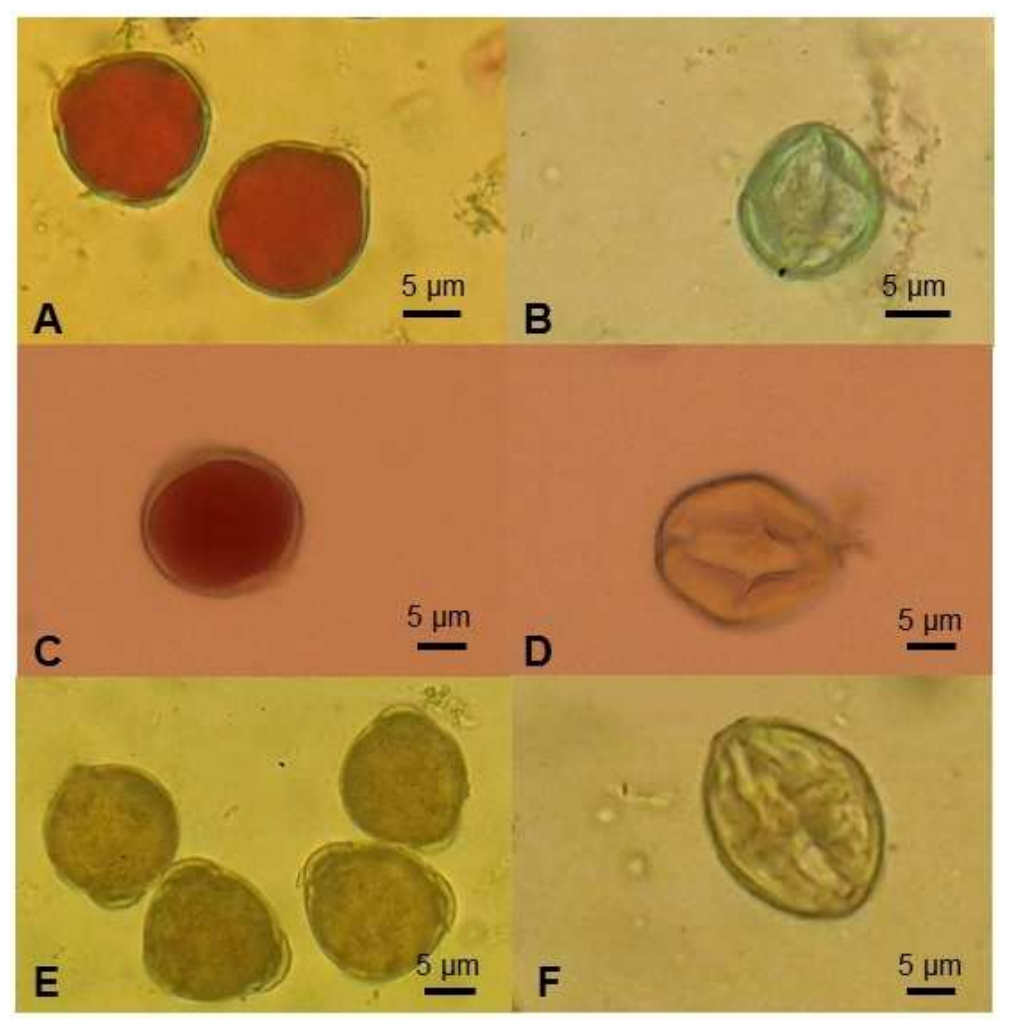

FIGURA 1. Grãos de pólen de $B$. orellana corados com diferentes corantes. A-B reativo de Alexander, pólen viável e inviável respectivamente; C-D Polens corados com Carmim, pólen viável e inviável respectivamente; E-F Polens corados com Lugol, pólen viável e inviável respectivamente. Fonte: Os autores. 
Nos testes com lugol a coloração dos polens viáveis apresenta-se marrom devido uma reação química que acontece entre o iodo e a molécula de amido, enquanto os inviáveis apresentam coloração amarela clara ou transparente devido à ausência de amido (PAGLIARINI \& POZZOBON, 2004), sendo assim destaca-se que os polens de $B$. orellana possuem amido como material de reserva.

A solução de Alexander permite a distinção entre polens viáveis e inviáveis corando de forma diferenciada a celulose da parede do grão de pólen, em verdeclaro-azulado, e o protoplasma, em púrpura, facilitando a distinção. O método utiliza solução tripla, composta por orange $\mathrm{G}$, fucsina ácida e verde malaquita. A fucsina ácida é um corante específico para DNA, corando o citoplasma de vermelho; o verde malaquita colore de verde a parede do grão de pólen e o orange $G$ é um intensificador (ALEXANDER, 1980).

As porcentagens de viabilidade polínica entre os corantes não se diferiram estatisticamente, conforme demonstrado na Figura 2. Com o corante reativo de Alexander foi possível distinguir visualmente e com maior precisão os polens viáveis dos inviáveis. Sendo, portanto o mais recomendado pelo aspecto da coloração diferencial dos gametas masculinos viáveis e inviáveis do urucum.

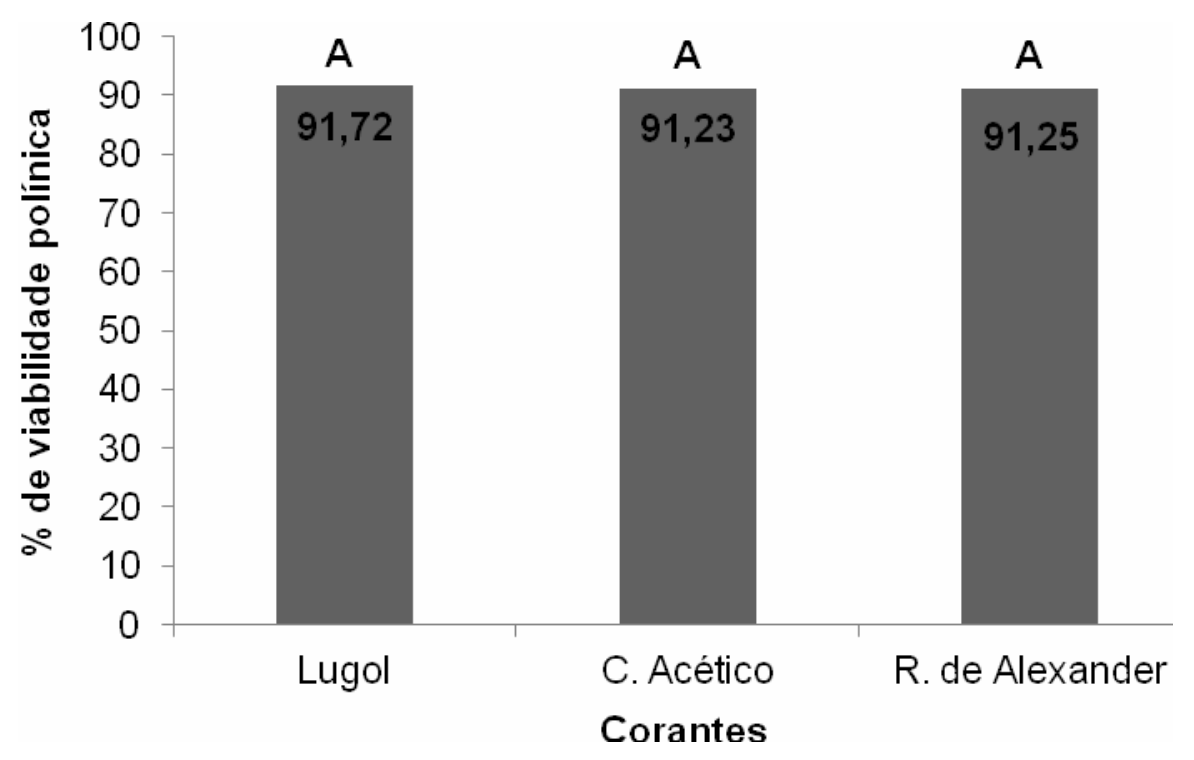

FIGURA 2: Comparação da porcentagem de viabilidade polínica em B.orellana entre os corantes carmin acético $2 \%$,

Fonte: Os autores. lugol e reativo de Alexander.

$\mathrm{Na}$ comparação entre as populações observa-se que a população de NB obteve média $87,72 \%$ diferindo-se estatisticamente das demais populações que mantiveram médias $>90 \%$ (Figura 3). No estudo realizado por GOMES et al., (2013) com a espécie Mauritia flexuosa, também foi encontrado um alto potencial de viabilidade polínica com médias $>95 \%$. Os resultados obtidos no presente estudo revelam que os gametas masculinos de $B$. orellana têm alto potencial de fecundidade, pois quanto mais elevada for à viabilidade dos polens, maior será o índice de fertilização. 


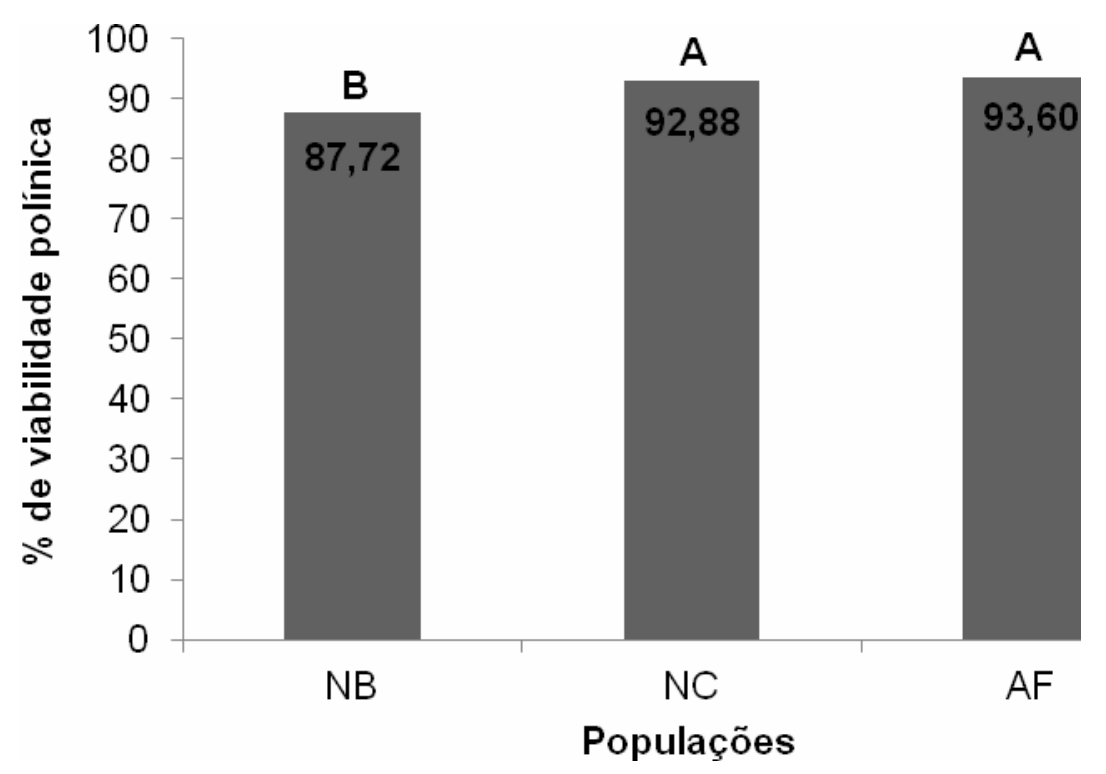

FIGURA 3: Comparação da porcentagem de viabilidade polínica em B.orellana entre as populações Nova Bandeirantes (NB), Nova Canaã (NC) e Alta Floresta (AF).

Fonte: Os autores.

Conforme apresentado na Tabela 1 a população NB manteve média inferior e diferente estatisticamente das outras duas populações, para os três corantes utilizados no presente estudo. Quando a porcentagem de viabilidade polínica foi comparada entre os genótipos, observa-se que os genótipos 1 e 5 da população NB obtiveram menores médias, 83,88 e $74,69 \%$ respectivamente, diferindo-se estatisticamente dos demais genótipos (Tabela 2).

De acordo com NASCIMENTO et al., (2012), grãos de pólen com baixa viabilidade resultam, geralmente, em um pobre pegamento de frutos. Recomendase, portanto que seja evitado coletar pólen dos genótipos 1 e 5 da população NB, quando da realização de cruzamentos manuais. Recomenda-se também que esses dois genótipos não sejam utilizados em programas de melhoramento.

TABELA 1: Porcentagem de viabilidade polínica em três populações de B.orellana com os corantes carmin acético, lugol e reativo de Alexander.

\begin{tabular}{cccc}
\hline \multirow{2}{*}{ Populações } & \multicolumn{3}{c}{ Corantes } \\
\cline { 2 - 4 } & Lugol & C. Acético & R. de Alexander \\
\hline $\mathrm{NB}$ & $88,00 \mathrm{Ab}$ & $87,51 \mathrm{Ab}$ & $87,64 \mathrm{Ab}$ \\
$\mathrm{NC}$ & $93,59 \mathrm{Aa}$ & $92,87 \mathrm{Aa}$ & $92,18 \mathrm{Aa}$ \\
$\mathrm{AF}$ & $93,55 \mathrm{Aa}$ & $93,32 \mathrm{Aa}$ & $93,92 \mathrm{Aa}$ \\
\hline $\mathrm{CV}(\%)=6,87$ & & &
\end{tabular}

Médias seguidas pelas mesmas letras, maiúsculas nas linhas e minúsculas nas colunas, não diferem entre si pelo teste de Tukey $5 \%$.

Fonte: Os autores. 
Para as populações NC e AF todos os genótipos apresentaram viabilidade polínica acima de $90 \%$, portanto todos podem ser utilizados como fonte de gameta masculino para polinizações artificiais e em programas de melhoramento.

TABELA 2: Porcentagem de viabilidade polínica de cinco genótipos de B.orellana provenientes das populações Nova Bandeirantes (NB), Nova Bandeirantes (NB), Nova Canaã (NC) e Alta Floresta (AF).

\begin{tabular}{cccc}
\hline \multirow{2}{*}{ Indivíduos } & \multicolumn{3}{c}{ Populações } \\
\cline { 2 - 4 } & $\mathbf{N B}$ & $\mathbf{N C}$ & $\mathbf{A F}$ \\
\hline 1 & $83,88 \mathrm{Bb}$ & $91,83 \mathrm{Aa}$ & $94,57 \mathrm{Aab}$ \\
2 & $92,19 \mathrm{Aa}$ & $94,33 \mathrm{Aa}$ & $90,09 \mathrm{Ab}$ \\
3 & $92,93 \mathrm{Aa}$ & $92,73 \mathrm{Aa}$ & $97,83 \mathrm{Aa}$ \\
4 & $94,91 \mathrm{Aa}$ & $93,65 \mathrm{Aa}$ & $91,92 \mathrm{Aab}$ \\
5 & $74,69 \mathrm{Bc}$ & $91,87 \mathrm{Aa}$ & $93,57 \mathrm{Aab}$ \\
\hline
\end{tabular}

$\mathrm{CV}(\%)=6,87$

Médias seguidas pelas mesmas letras, maiúsculas nas linhas e minúsculas nas colunas, não diferem entre si pelo teste de Tukey $5 \%$.

Fonte: Os autores.

Diversos estudos vêm comprovando a eficiência desses corantes na técnica de estimativa da viabilidade polínica. FRESCURA et al., (2012) observaram uma alta viabilidade polínica para a maioria das populações de Polygala paniculata L. analisadas utilizando-se o corante reativo de Alexander. PICCININI et al., (2012), ao analisarem diferentes genótipos de Eragrostis plana também observaram uma alta viabilidade polínica em todos os genótipos avaliados através do uso da solução de Alexander.

\section{CONCLUSÃO}

A espécie $B$. orellana apresentou alta viabilidade polínica, demonstrando alto potencial para a fecundidade dos gametas masculinos. Os três corantes utilizados foram eficientes na coloração e diferenciação dos polens viáveis e inviáveis sendo, portanto, recomendados para verificação da viabilidade polínica da espécie.

\section{REFERÊNCIAS}

ALEXANDER, M. P. A. Versatile stain for pollen, fungi, yeast and bacteria. Stain Technology, Baltimore, v. 1, n. 5, p. 13-18,1980.

DAFNI, A. Pollination ecology: - a pratical approach. New York, Oxford University Press, 1992. 250p.

FERREIRA, D. F. Sisvar: a computer statistical analysis system. Ciência e Agrotecnologia (UFLA), v. 35, n.6, p. 1039-1042, 2011.

FRESCURA, V. D.; LAUGHINGHOUSE IV, H. D.; CANTODOROW, T. S.; TEDESCO, S. B. Pollen viability of Polygala paniculata L. (Polygalaceae) using different staining methods. Biocell, v. 36, n. 3, p. 143-145, 2012. 
GOMES, A. D.; ROSSI, A. A. B.; DARDENGO, J.; SILVA, B.; SILVA, I. Razão sexual e viabilidade polínica de Mauritia flexuosa L.(Arecaceae). Enciclopédia Biosfera, Goiânia, v. 9, n. 17, p. 2864-2870, 2013.

KEARNS, C. A.; INOUYE, D. W. Techiniques for pollination biologists. University Press of Colorado, 1993.

MUNHOZ, M.; LUZ, C. F. P.; MEISSNER FILHO, P. E.; BARTH, O. M.; REINERT, F. Viabilidade polínica de Carica papaya L.: uma comparação metodológica. Revista Brasileira de Botânica, [São Paulo], V. 31, n. 2, p. 209-214, 2008.

NASCIMENTO, W. M.; GOMES, E. M. L.; BATISTA, E. A.; FREITAS, R. A. Utilização de agentes polinizadores na produção de sementes de cenoura e pimenta-doce em cultivo protegido. Horticultura Brasileira, Brasília, v. 30, n. 3, p. 494-498, 2012.

PAGLIARINI, M. S.; POZZOBON, T. Meiose em vegetais: um enfoque para a caracterização de germoplasma. In: CURSO DE GENÉTICA APLICADO A RECURSOS VEGETAIS, 2. Documentos, Brasília: Embrapa recursos genéticos e biotecnologia-DF, p. 24-41, 2004.

PICCININI, F.; FRESCURA, V. D.; LAUGHINGHOUSE IV, H. D.; PEREZ, N. B.; TEDESCO, S. B. Pollen viability of Eragrostis plana genotypes from diferente geographic populations in rio grande do sul. Enciclopédia Biosfera, v.8, n.15; p. 1316, 2012. 